\title{
Bromocriptine in Parkinson's Disease: Results Obtained With High and Low Dose Therapy
}

\author{
J. David Grimes
}

\begin{abstract}
The results obtained with high and low dose bromocriptine therapy were compared in a review assessing the per cent of patients showing improvement (not taking account of the extent of improvement). It is concluded that the response rate with low dose bromocriptine is as good as that obtained with high dose therapy for both de novo and levodopa treated patients. The incidence of adverse effects is similar in the high and low dose treatment groups: More levodopa reduction results in a higher daily bromocriptine requirement. A statistical analysis of 61 bromocriptine-levodopa treated patients showed no positive correlation between bromocriptine dose and severity or duration of Parkinson's disease.
\end{abstract}

RÉSUMÉ: Nous revoyons le pourcentage de patients améliorés de façon comparative avec des doses de bromocriptine élevées ou basses. Nous concluons que la réponse obtenue à des doses basses est aussi bonne que celle observée avec des doses fortes tant chez les patients de novo que chez ceux recevant de la Lévodopa. L'incidence d'effets secondaire est semblable dans les groupes à haute ou basse dose. Plus il y a réduction de la Lévodopa, plus il faut utiliser de bromocriptine. Une étude statistique chez 61 patients ne montra aucune corrélation positive entre la dose de bromocriptine et la sévérité ou la durée de la maladie de Parkinson.

Can. J. Neurol. Sci. 1984: 11:225-228

Experience with bromocriptine has been collected over the past ten years. An initial low dose study by Calne et al. (1974a) using doses less than $30 \mathrm{mg}$ daily was followed by other studies (Calne et al., 1974 b; Teychenne et al., 1975) in which bromocriptine was used in doses up to $75 \mathrm{mg}$ daily and levodopa was stopped. Subsequent studies used both low (Fahn et al., 1980; Grimes and Hassan, 1981) and high (Kartzinel et al., 1976 a; Lieberman et al., 1976 a) doses of bromocriptine combined with varying reductions of levodopa. De novo patients have been treated with both high (Less and Stern, 1983) and low (Teychenne et al., 1982) doses.

The indications for bromocriptine have slowly become more clear. The drug is of no consistent benefit in patients who have not previously responded to levodopa (Parkes et al., 1976). Lewitt and Calne (1981) documented that the best results are obtained when bromocriptine addition is combined with levodopa reduction in patients who have end-of-dose deterioration and levodopa induced dyskinesias. Parkes et al. (1976) noted that the least disabled patients showed the greatest improvement. Hoehn (1981) commented in a general review of bromocriptine therapy, that the degree of improvement is not dependent upon the age of the patient or on the duration of the disease.

The method of bromocriptine addition has varied from very slow (Teychenne et al., 1982; Grimes and Hassan, 1981), to extremely rapid in combination with domperidone to block gastric upset (Quinn et al., 1981).

The trend has been towards a lower daily dosage of bromocriptine. Fahn et al. (1980) first addressed the question of low dose bromocriptine by reporting a group of patients who responded to doses of less than $25 \mathrm{mg}$ daily; Teychenne et al. (1982) subsequently reported benefit with mean daily doses of
$15 \mathrm{mg}$. High doses have been noted to cause both an increase in adverse effects (Teychenne et al., 1975; Kartzinel et al., 1976 a) and worsening of Parkinsonism (Teychenne et al., 1978; Koller et al.. 1979).

The question of bromocriptine dose and disease severity has recently been reviewed by Larsen et al. (1983). They concluded that patients with mild Parkinson's disease can be treated with lower doses of bromocriptine (20 to $40 \mathrm{mg} /$ day), but higher doses (40 to $90 \mathrm{mg} /$ day) are required in patients with severe deficits.

This review will compare the results and adverse effects with both high and low doses of bromocriptine. New data will be presented addressing the question of bromocriptine dose in relation to disease stage and duration.

\section{Materials ANd Methods}

For this review a mean daily bromocriptine dose of over $55 \mathrm{mg}$ was accepted as a high dose; a dose of less than $30 \mathrm{mg}$ daily was classed as low dose therapy. Improvement was accepted as the per cent of patients treated improving as stated by the author with no attempt to specifically grade the degree of improvement.

The literature on bromocriptine therapy over the last ten years was reviewed. The studies selected for this review were those where a definite per cent improvement and incidence of adverse effects could be calculated. Levodopa adjustments also had to be clearly defined.

In addition to the above literature review, data was studied on 61 patients who participated in two Multi-Centre trials organized by Sandoz Canada. This data was statistically assessed 
Table 1: A comparison of different groups of low and high dose bromocriptine treated patients.

\begin{tabular}{lccccc}
\hline \hline & $\begin{array}{c}\text { Number of } \\
\text { Patients }\end{array}$ & $\begin{array}{c}\text { Mean } \\
\text { Dose } \\
(\mathbf{m g} / \text { day) }\end{array}$ & $\begin{array}{c}\text { Response } \\
\text { Rate } \\
(\%)\end{array}$ & $\begin{array}{c}\text { Levodopa } \\
\text { Reduction } \\
(\%)\end{array}$ & $\begin{array}{c}\text { Adverse } \\
\text { Effects } \\
(\%)\end{array}$ \\
\hline High Dose Group & 89 & 88 & 66 & 71 (range $31-100)$ & 59 \\
Low Dose Group & 89 & 24 & 67 & (range 0-34) \\
\hline
\end{tabular}

to try and document a correlation present between mean daily dose of bromocriptine and stage (Hoehn and Yahr, 1967) and duration of Parkinson's disease. These patients had been treated for daily fluctuations or late levodopa failure. The first study included 28 patients treated with up to $80 \mathrm{mg}$ of bromocriptine daily (mean $35 \mathrm{mg}$ ); the second study was of 33 patients who received a maximum of $30 \mathrm{mg}$ daily (mean $22 \mathrm{mg}$ ). These studies were analyzed individually and combined. The dose of bromocriptine after six months of treatment was compared with the stage on initiation of treatment. This was studied with graphic representation and correlation coefficients; $P$ values were calculated. The duration of Parkinson's disease was defined as the number of years from the date of diagnosis to the end of the study (six months after a patient entered the trial). The data was analyzed with scatter diagrams; correlation coefficients were calculated from a linear regression model and $\mathrm{P}$ values were assessed.

The high dose bromocriptine group consisted of 89 patients collected from five separate studies (Glantz et al., 1981; Quinn et al., 1981; Kartzinel et al., 1976 a; Kartzinel et al., 1976 b; Lieberman et al., 1976 a). The low dose bromocriptine group included 89 different patients from four separate series (Grimes et al., 1983 a; Grimes and Hassan, 1981; Fahn et al., 1980; Lieberman et al., 1976 b). Response in de novo patients was assessed by reviewing the results obtained with 50 high dose (mean 70mg daily) patients reported by Lees and Stern (1983) and comparing them with 58 low dose (mean $19 \mathrm{mg}$ daily) patients collected from three separate series (Grimes et al., $1983 \mathrm{~b}$; Teychenne et al., 1982; Rinne and Marttila, 1978).

\section{RESULTS}

The high dose bromocriptine (mean daily dose $88 \mathrm{mg}$ ) group had a response rate of 66 per cent. Levodopa was reduced by a mean of 71 per cent (range 31-100) and 59 per cent of patients suffered adverse effects. Sixty-seven per cent of the low dose (mean daily dose $(24 \mathrm{mg}$ ) bromocriptine group showed improvement. Levodopa was decreased by an average of $18 \mathrm{per}$ cent (range 0-34) and adverse effects were documented in 52 per cent of the patients. These high and low dose bromocriptine treated patients are compared in Table 1.

The mean daily dose, response rate and incidence of adverse effects for the high and low dose de novo groups are compared in Table 2.

Combined data for 61 patients comparing bromocriptine dose and disease stage showed the following. After six months of treatment stage II patients required a mean daily dose of $40 \mathrm{mg}$; stage III patients took $28 \mathrm{mg}$ daily and stage IV patients received an even lower mean daily dosage of $23 \mathrm{mg}$. These data are
Table 2: A comparison of different groups of de novo patients treated with high and low doses of bromocriptine.

\begin{tabular}{lcccc}
\hline \hline & $\begin{array}{c}\text { Number of } \\
\text { Patients }\end{array}$ & $\begin{array}{c}\text { Mean } \\
\text { Dose } \\
(\mathbf{m g} / \text { day })\end{array}$ & $\begin{array}{c}\text { Response } \\
\text { Rate } \\
(\%)\end{array}$ & $\begin{array}{c}\text { Adverse } \\
\text { Effects } \\
(\%)\end{array}$ \\
\hline $\begin{array}{l}\text { High Dose } \\
\text { Group }\end{array}$ & 50 & 70 & 56 & 50 \\
$\begin{array}{l}\text { Low Dose } \\
\text { Group }\end{array}$ & 58 & 19 & 64 & 49 \\
\hline
\end{tabular}

displayed graphically in Figure 1. Further analysis of this data shows a correlation coefficient of minus $0.275(\mathrm{P}=0.032)$. Hence, no direct evidence of a positive relationship between mean dosage of bromocriptine and disease stage was found.

Graphic representation of the mean daily dose of bromocriptine and the duration of Parkinson's disease is presented in a scatter diagram (figure 2) and no positive correlation could be identified. In order to further study the relationship between mean dose and duration, a linear regression model was fitted to the data (61 patients). This produced a correlation coefficient of 0.29 $(P=0.0238)$ which is significant. A closer examination of the data was done by calculating Cook's D statistic and the residual values. It was found that patient number three had a great influence in his neighborhood as indicated by his large Cook's $D$ value and his large studentized residual value. Patient number three was on a dose of $60 \mathrm{mg}$ of bromocriptine and had Parkinson's disease for 25 years. This patient was removed from the data and the linear model was fitted again resulting in a correlation

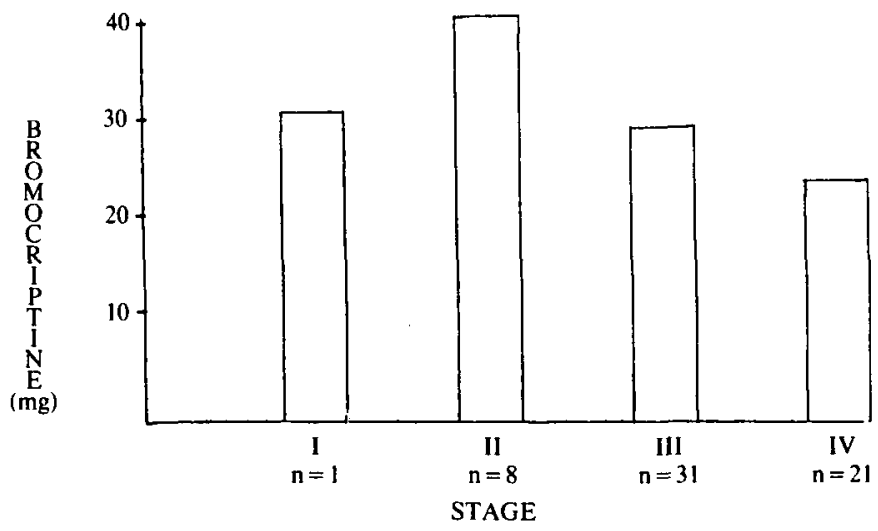

Figure 1 - The mean daily dose of bromocriptine compared with the stage of Parkinson's disease. $(n=$ number of the 61 patients in each stage $)$. 


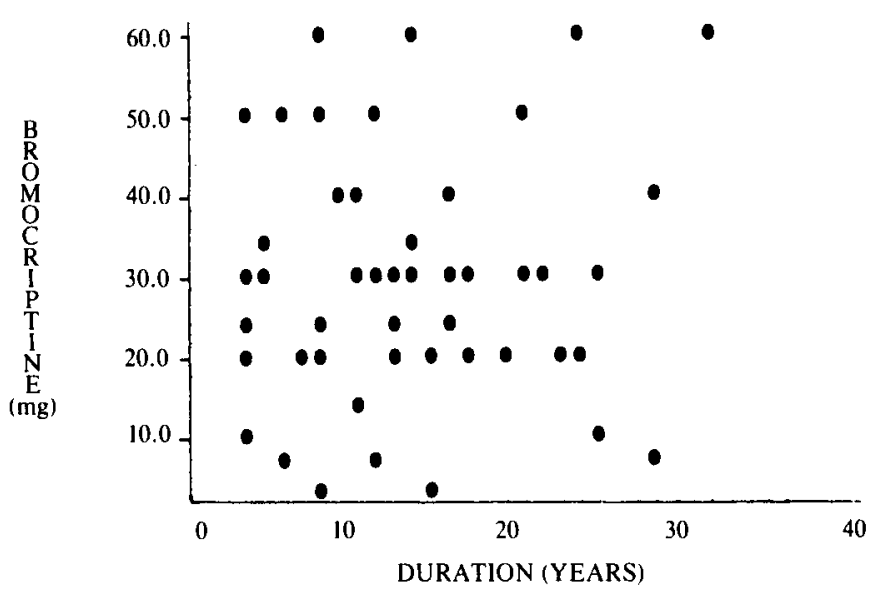

Figure 2 - The mean daily dose of bromocriptine compared with the duration of Parkinson's disease.

coefficient of $Y=0.207$ which was not significant $(P=0.1133$ ). Therefore analysis of this data shows no significant trend or positive relationship between the mean dosage of bromocriptine and the duration of Parkinson's disease.

\section{DISCUSSION}

This literature review documents that the response rate to high and low dosages of bromocriptine is about equal. This study only assessed the per cent of patients showing improvement and not the degree of improvement. Previous authors (Calne, 1978; Quinn et al., 1981) have stated that much clearer benefit is apparent when high dose therapy is used. Bromocriptine therapy has gone through a number of dosage phases in the past 10 years. Initial low dose studies were followed by very high dose studies with partial or complete levodopa replacement. In the past few years the trend has been towards much lower doses of bromocriptine with little or no levodopa decrease. The work of Teychenne et al. (1982) has generated interest in extremely low (mean 15mg daily or less) doses and he has reported significant improvement in Parkinsonism. Little other data however, is available using such small amounts of the drug.

The method of addition of bromocriptine is important; rapid dosage increases lead to an increase in adverse effects (Quinn et al., 1981). It has also been suggested (Teychenne et al., 1982) that this method may miss a point of low dose drug response. It is not at all clear if the method of very slow introduction leads to a lower effective bromocriptine dose. Analysis of our present literature review shows that a large levodopa reduction is associated with a higher mean daily dose of bromocriptine. Certainly some of the recently reported effectiveness of low dose bromocriptine is related to the present trend towards little or no levodopa decrease. The value of combination levodopa bromocriptine therapy has been recognized (Caraceni et al., 1977) and it is accepted that bromocriptine is less potent than levodopa (Rinne and Marttila, 1978; Duvoisin et al., 1980). Kartzinel et al. (1976b) demonstrated significant improvement with both low and high doses of bromocriptine; however, a better grade of response to high dose therapy has been more frequently reported (Parkes et al., 1976; Teychenne et al., 1978).
Comparison of the low and high dose de novo bromocriptine treated patients shows a slightly better response rate ( 64 vs 56 per cent) in favour of the low dose group. The grade of improvement was not assessed; however, Lees and Stern (1983) state that their maximum tolerated bromocriptine de novo group, only achieved a degree of improvement comparable to that seen in mildly incapacitated patients treated with levodopa. The method of bromocriptine introduction was much slower in the low dose de novo studies reviewed.

The incidence of adverse effects with high and low dose therapy was the same in the de novo patients reviewed. The high dose levodopa-bromocriptine treated group had a slightly higher occurrence of side-effects ( 59 vs 52 per cent) compared to the lower dose patients. In trying to estimate the incidence of adverse effect it was difficult to separate serious drug and dose limiting events from more transient minor occurrences. Most authors have reported a higher incidence of adverse effects with increasing dose. Kartzinel et al. (1976b) however noted no significant difference in the number of adverse reactions for 20 patients treated with both low and maximum tolerated bromocriptine doses. The results of this present review are basically in agreement with this and again demonstrate the frequent incidence of adverse effect with even low dose bromocriptine therapy.

It is difficult to compare the results of various series extracted from the literature. Different workers have used varying groups of patients, methods of bromocriptine introduction, and levodopa alteration. In some early studies, bromocriptine was increased until adverse effects occurred. The response rate in more recent (usually lower dose) studies may be improved because neurologists have learned to select patients who have specific parkinsonian problems that have been shown to respond to bromocriptine.

Our data reveals no positive correlation between bromocriptine dose and severity or duration of Parkinson's disease. The patients with more severe, longer duration disease, gained improvement from a lower mean daily dose of bromocriptine. These results are different from those of Larsen et al. (1983). This difference however may be related to patient selection, bromocriptine dose limits, or methods of bromocriptine and levodopa dose adjustment.

This review shows that the response rate with low dose bromocriptine is as good as that obtained with high dose therapy for both de novo and levodopa treated patients. The incidence of adverse effects is similar in both treatment groups. Large reductions in levodopa dosage result in a much higher daily bromocriptine requirement. Low dose bromocriptine now has an established role in the management of Parkinson's disease. The best long-term results are in patients with end-of-dose failure and levodopa induced dyskinesias. The results with de novo patients have been equivocal; the use of low dose levodopa combined with the early addition of low dose bromocriptine is being explored.

\section{ACKNOWLEDGEMENTS}

Statistical assessment of the computerized Multi-Centre patient data was performed by Yves Lalonde of Sandoz Canada. Gayla Desjardins typed the manuscript and prepared the tables, figures and references.

This work was supported by a grant from the Parkinson Foundation of Canada. 


\section{REFERENCES}

Calne DB, Teychenne PF, Claveria LE, Eastman R. Greenacre JK, Petrie A (1974a) Bromocriptine in Parkinsonism. Br Med J 4:442-444.

Calne DB, Teychenne PF, Leigh PN, Bamji AN, Greenacre JK (1974b) Treatment of Parkinsonism with bromocriptine. Lancet 2:1355.

Calne DB (1978) Dopaminergic agonists in the treatment of Parkinsonism. Clin Neuro Pharm 3:153-166.

Caraceni TA, Celano I, Parati E. Girotti F (1977) Bromocriptine alone or associated with L-dopa plus benserazide in Parkinson's disease. J Neurol Neurosurg Psychiatry. 40:1142-1146.

Duvoisin RC, Mendoza MM, Yahr MD (1980) A comparative study of bromocriptine and levodopa in Parkinson's disease. Ergot Compounds and Brain Function: Neuroendocrine and Neuropsychiatric Aspects. Eds M Goldstein et al. 271-275. Raven Press, New York.

Fahn S, Cote LJ, Barretl RE, Snider SR (1980) Further experiences with low doses of bromocriptine in Parkinson's disease. Ergot Compound and Brain Function: Neuroendocrine and Neuropsychiatric Aspects. Eds M Goldstein et al. 255-259. Raven Press, New York.

Glantz R, Goetz CG, Nausieda PA, Weiner WJ, Klawans HL (1981) The effect of bromocriptine (BCT) on the On-off phenomenon. J Neural Trans 52:41-47.

Grimes JD, Hassan MN (1981) Method of bromocriptine addition to the drug regime of patients with advanced Parkinson's disease. Can J Neurol Sci 8:31-34.

Grimes JD, King DB, Kofman OS, Molina-Negro P, Wilson AF, Bouchard $S$ (1983a) The use of low dose bromocriptine to treat end-of-dose failure in levodopa treated Parkinson's disease patients: The results of a Multi-Centre study. Can J Neurol Sci 10:132.

Grimes JD, Delgado MR, Gray P (1983b) Low dose bromocriptine therapy in "De Novo" Parkinson's disease: Indications, dosage, initial response rate, and adverse effects. Neurology 33(2):112.

Hoehn MM, Yahr MD (1967) Parkinsonism: Onset, progression, and mortality. Neurology 17:427-442.

Hoehn MM (1981) Bromocriptine and Its use in Parkinsonism. J Am Geriatr Soc 29(6):251-258.

Kartzinel R, Shoulson I, Calne DB (1976a) Studies with bromocriptine Part 2. Double-blind comparison with levodopa in idiopathic parkinsonism. Neurology 26:511-513.
Kartzinel R, Teychenne P, Gillespie MM, Perlow M, Gielen AC, Sadowsky DA, Calne DB (1976b) Bromocriptine and levodopa (with or without carbidopa) in parkinsonism. Lancet 7:272-275.

Koller WC, Weiner WJ, Nausieda PA, Klawans HL (1979) Bromocriptine: Decreased clinical effects at higher doses. Neurology 29:1439.

Larsen TA, Newman RP, LeWitt PA, Calne DB (1983) Bromocriptine dosage and the severity of Parkinson's disease. Neurology 33(2):137.

LeWitt PA, Calne DB (1981) Recent advances in the treatment of Parkinson's disease: The role of bromocriptine. J Neural Trans 51:175-184.

Lieberman A, Kupersmith M, Estey E, Goldstein M (1976a) Treatment of Parkinson's disease with bromocriptine. New Engl J Med 25:1400-1403.

Lieberman A, Zolfaghari M, Boal D, Hassouri H, Vogel B, Battista A. Fuxe K, Goldstein M (1976b) The antiparkinsonian efficacy of bromocriptine. Neurology 26:405-409.

Parkes JD, Marsden CD, Donaldson I. Galea-Debono A, Walters J, Kennedy G, Asselman P(1976) Bromocriptine treatment in Parkinson's disease. J Neurol Neurosurg Psychiatry 39:184-193.

Quinn N, Illas A, Lhermitte F, Agid Y (1981) Bromocriptine and domperidone in the treatment of Parkinson's disease. Neurology 31:662-667.

Rinne UK, Marttila R (1978) Brain Dopamine Receptor Stimulation and the Relief of Parkinsonism: Relationship between bromocriptine and levodopa. Ann Neurol 4:263-267.

Stern GM, Lees AJ (1983) Sustained bromocriptine therapy in 50 previously untreated patients with Parkinson's disease. Adv Neurol 37:17-21.

Teychenne PF, Leigh PN, Reid JL, Calne DB, Greenacre JK, Petrie A (1975) Idiopathic parkinsonism treated with bromocriptine. Lancet 2:473-476.

Teychenne PF, Pfeiffer RF, Bern SM, McInturff D, Calne DB (1978) Comparison between lergotrile and bromocriptine in parkinsonism. Ann Neurol 3:319-324.

Teychenne PF, Bergsrud D, Racy A, Elton RL, Vern B (1982) Bromocriptine: Low-dose therapy in Parkinson disease. Neurology $32: 577-583$ 